\title{
Within-season divorce in Blue Tits (Cyanistes caeruleus)
}

\author{
Alain Jacot $\cdot$ Mihai Valcu $\cdot$ Bart Kempenaers
}

Received: 27 April 2009/Revised: 9 October 2009/Accepted: 16 November 2009/Published online: 11 December 2009

(C) The Author(s) 2009. This article is published with open access at Springerlink.com

\begin{abstract}
Divorce between breeding seasons, i.e. mate change while the old breeding partner is still alive, has been well-studied in several bird species. It can be viewed either as the result of reproductive decisions of individuals to maximize their own fitness or as the outcome of intra-sexual competition for mating opportunities. In contrast, divorce within a breeding season-also referred to as rapid mate switching-has received much less attention. Withinseason divorce may occur after sudden changes in environmental conditions, such as those causing the disappearance or devaluation of nesting sites or territories, or when better breeding partners become available. Within-season divorce can be initiated by a member of the pair, or it can be the result of a take-over by an unpaired individual that competes for access to the resource. During a field experiment investigating the effects of limiting nesting sites on reproductive behaviour in Blue Tits, we recorded several cases of withinseason divorce. The rate of divorce was not related to the experimental nest-site limitation, and pairs that changed their partner suffered reduced reproductive success compared to faithful pairs. Although there were no differences in the timing of breeding, clutch size or hatching success, pairs with a new partner also suffered a reduced fledging success, which was partly explained by complete brood failures. This study highlights that the pair bond prior to egg laying can be unstable when conditions force individuals to compete for a
\end{abstract}

Communicated by T. Friedl.

A. Jacot $(\square) \cdot$ M. Valcu $\cdot$ B. Kempenaers

Department of Behavioural Ecology and Evolutionary Genetics,

Max Planck Institute for Ornithology,

Eberhard-Gwinner-Strasse 5,

82319 Seewiesen, Germany

e-mail: jacot@orn.mpg.de new partner or nest site and indicates the importance of the correct timing of divorce within the breeding cycle.

Keywords Blue Tit - Cyanistes caeruleus .

Intrasexual competition - Rapid mate switching .

Within-season divorce

\section{Introduction}

The mating system of most bird species is characterized by social monogamy (Lack 1968) where breeding partners are occasionally changed between breeding attempts. Re-mating with a new partner can be triggered by the death of the former partner (i.e. "widowed re-mating") or by the reduced probability of finding the former partner (Cezilly and Johnson 1995; Ens et al. 1996). However, re-mating can also result from a strategic decision of at least one partner while both individuals are still alive (i.e. divorce; Choudhury 1995). In many bird species, divorce has been viewed as a reproductive strategy whereby individuals can maximize their own fitness by gaining direct or indirect (genetic) fitness benefits from mating with a new partner (Ramsay et al. 2000; Green et al. 2004; Moody et al. 2005), although the behavioural processes that ultimately result in a divorce have rarely been studied.

Models predict that individuals should only divorce if the expected future gain in fitness with the new mate will exceed the expected gain with the old mate (McNamara and Forslund 1996; McNamara et al. 1999). The causes of divorce and the fitness consequences of divorcing individuals have been investigated in several bird species (Jeschke and Kokko 2008). In one study, Great Tits Parus major that raised an experimentally reduced brood in the previous year were more likely to mate with a new partner 
(Linden 1991), which indicates that previous breeding performance may influence the propensity to divorce. In the Oystercatcher Haematopus ostralegus, divorcing individuals were found to increase their lifetime reproductive success, but the fitness gain depended on the status of their new mating partner (Heg et al. 2003). In one study on the Blue Tit Cyanistes caeruleus, the breeding success of female divorcees decreased in one study (Pampus et al. 2005), whereas in two other studies, there were potential fitness benefits from divorce (Blondel et al. 2000; Valcu and Kempenaers 2008). The results of a long-term study by Valcu and Kempenaers (2008) demonstrated that once territory quality and breeding dispersal were taken into account, both males and dispersed females increased their breeding success. The same study also suggested that divorce can be independent of mating decisions by the former pair members and may be triggered by femalefemale competition, whereby a dominant female evicts the former mate.

These studies show that the fitness consequences of divorce are often complex and may partly depend on ecological factors that affect the costs of mate searching and mate sampling as well as the probability of establishing or finding a vacant territory. A crucial, although largely unexplored factor affecting the probability of finding an optimal partner and territory may be the time within the breeding cycle when divorce and re-mating occurs. Fitness costs may arise whenever there are time-constraints to finding an optimal mate, i.e. divorcing shortly before the onset of the breeding season should incur higher costs than divorce and re-mating during the non-breeding season.

Whenever environmental conditions change rapidly, thereby altering breeding conditions and the availability of nesting sites or mating partners shortly before the breeding season, individuals may respond flexibly and adopt reproductive strategies to ensure some degree of breeding success. Such strategies may involve intraspecific brood parasitism (Gowaty and Bridges 1991; Jacot et al. 2009), paternity gain via extra-pair copulations (Kempenaers et al. 2001) or re-mating with a new partner. The term 'rapid mate switching' can also be used to refer to divorce and re-mating that occur during the breeding season. This type of divorce may be more common than currently reported (e.g. $14 \%$ in a study on the Blackbird Turdus merula, Wysocki 2004), but its causes and consequences have received relatively little attention. One cause may be predator-induced mortality of one partner, where the other individual has to find a new mate, as suggested in a field study on the European Starling Sturnus vulgaris (Pinxten et al. 1993). In contrast, withinseason divorce may also be initiated when the old partner is still alive. In a correlative and experimental study, female Black-capped Chickadees Parus atricapilla were observed to be more likely to divorce their current partner shortly before the breeding season when a higher ranking male became available (Otter and Ratcliffe 1996; Ramsay et al. 2000). These examples highlight the fact that variation in male availability and quality can influence female mate choice decisions even shortly before breeding onset. The availability of nesting sites is another important ecological factor known to fluctuate over time (Newton 1994); it leads to intense competition among males, females or pairs, whereby dominant individuals are expected to gain access to these resources (Newton 1994). A limitation of nesting sites may thus lead to a short-term re-shuffling of breeding pairs (and hence within-season divorce) so that dominant males and females will manage to breed while sub-dominant individuals are evicted.

During an experimental field study, Jacot et al. (2009) investigated the effects of limiting the number of nesting sites on the mating and reproductive behaviour of the Blue Tit. During that study, we observed that several breeding pairs divorced shortly before breeding and subsequently re-mated with another individual. The main aims of this article are (1) to describe these incidences of within-season divorce shortly before egg laying and (2) to report and discuss an analysis of the consequences of within-season divorce on reproductive performance.

\section{Materials and methods}

We studied the effects of limiting nest sites on reproductive behaviour in a population of Blue Tits Cyanistes caeruleus breeding in nestboxes at Kolbeterberg (Vienna, Austria; $48^{\circ} 13^{\prime} 17^{\prime \prime} \mathrm{N}, 16^{\circ} 14^{\prime} 12^{\prime \prime} \mathrm{E}$ ). For a detailed account of the nest-site limitation experiment, see Jacot et al. (2009). In short, we reduced the number of nestboxes by $50 \%$ in two experimental plots a few days before egg laying started in the population (5 April) and kept two plots as controls. After the manipulation, the experimental plots contained ten and nine nestboxes, respectively, whereas the control plots had 22 and 17 boxes, respectively. Most importantly, we removed all nestboxes (active and inactive) in the afternoon of 5 April and erected new nestboxes in the same location (control plots) or at new locations (experimental plots) during the following night. All breeding pairs in the study site thereby experienced similar levels of disturbance-i.e. their nests were removed-but pairs in the experimental plots experienced stronger competition for a new nest site than pairs in the control plots.

During the pre-experimental period (mid-March to 5 April), each box was visited daily, and the identity of the individuals showing territorial behaviour was recorded. Unbanded individuals were trapped with a mist-net trap in the vicinity of the nestbox and marked with a unique combination of three plastic colour bands (AC Hughes, 
Middlesex, UK) and a numbered metal ring (Vogelwarte Radolfzell, Radolfzell, Germany). If the individuals were already banded, we recorded their colour bands. We identified or banded both individuals for $65 \%$ of the active nestboxes and only one individual in $26 \%$ of the boxes; in the remaining $9 \%$ of boxes, none of the individuals could be identified or captured. The number of individuals identified (none, one, or both) did not differ between the control and experimental plots $\left(\chi_{2}^{2}=2.90, P=0.23\right.$, $n=78$ ).

After the experimental manipulation on the 5 April, all nestboxes were visited again on a daily basis and the identity of the territorial individuals recorded. Clutch size, hatching success and fledging success were determined on the basis of regular nestbox checks. The identity of the breeding pair was confirmed by catching feeding adults when chicks were around 10 days old.

\section{Statistical analyses}

All statistical analyses were performed with R2.8.0 (R Development Core Team 2008). The function 'Im' was used to fit general linear models investigating the effects of mating status on clutch size and hatchling and fledgling number. Hatching and fledging success were analysed by performing generalized linear models (function ' $\mathrm{glm}$ ') with a binomial error distribution correcting for overdispersion. When investigating the effects of mating status on complete brood failure $(\mathrm{y} / \mathrm{n})$, we performed a Fisher's exact test for the count data.

\section{Results}

We identified the breeding adults before and after the nest site limitation experiment in 31 of a total of 56 active nests. Of these 31 active nests, seven (23\%) were owned by pairs mated with a new partner (three in control plots, four in experimental plots; Fig. 1). Within-season divorce was equally common in the experimental and control plots (Fisher's exact test; odds ratio $0.23, n=31, P=0.17$ ). Figure 1 illustrates the movement between the original and new nestboxes of each individual involved in within-season divorce. The breeding pairs of the seven cases of withinseason divorce consisted of 11 individuals that had been recorded in the study area before the experimental manipulation (solid arrows in Fig. 1) and three unbanded individuals whose origin was unknown (broken arrows in Fig. 1). The 11 known individuals originally came from ten different nestboxes, i.e. in one original nestbox both individuals re-mated with a new partner in the study area (see Fig. 1). The abandoned partners in the remaining nine original nestboxes could not be identified in the field or be captured afterwards, and it thus remains unknown whether these individuals dispersed, died or remained as floaters in the study site. In two cases of within-season divorce, individuals moved from an original box in a nest-sitelimited plot to a new box in a control plot. In both cases, females dispersed from their original territory to re-mate with a previous territory holder in control plots (see Fig. 1). In contrast, there was no case where an individual moved from a control plot and re-mated with an individual in a nest-site limited plot.

Males and females from faithful and divorced (withinseason) pairs did not differ in body mass, tarsus and wing

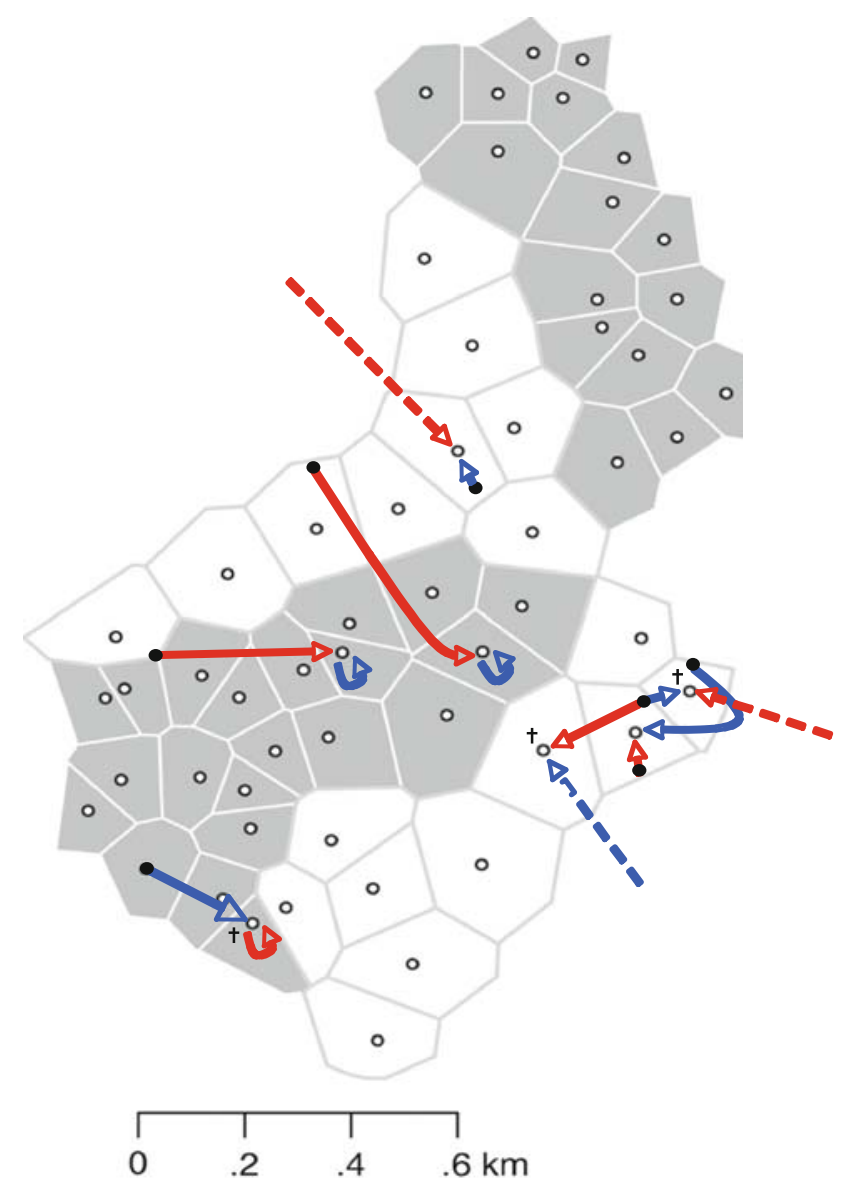

Fig. 1 Map of the study site indicating occupied territories after the experimental manipulation. The number of nestboxes were reduced by $50 \%$ in two plots (white) and the number was kept same in two other plots (grey). Note, however, that all original boxes were replaced. Open circles location of all new nestboxes after the experimental manipulation, filled circles original nestboxes before the nest-site limitation, which were occupied by a bird that was involved in a within-season divorce. Solid arrows movements of known individuals (11 individuals) before and after the manipulation, broken arrows unknown individuals (three individuals). Short solid arrows that re-curve to the same box in the control plots indicate individuals that remained at the same nest box after nest-site limitation. Red females, blue males. Complete brood failures are indicated with a cross 
length (separate $t$ tests for males and females; all $P>0.2$ ). In addition, faithful pairs $(n=24)$ and pairs that re-mated with a new partner $(n=7)$ from both treatments did not differ in lay date (faithful: $7.38 \pm 0.5$ days after manipulation, divorced: $\left.10.71 \pm 3.1 ; t_{29}=-1.17, P=0.25\right)$, clutch size (faithful: $11.4 \pm 0.4$, divorced: $11.2 \pm 0.9$; $\left.t_{29}=0.84, P=0.41\right)$ and number of chicks that hatched (faithful: $9.8 \pm 0.5$, divorced: $8.3 \pm 1.4 ; \quad t_{28}=1.14$, $P=0.27)$. In contrast, the number of fledglings differed significantly between the two groups (faithful: $8.7 \pm 0.8$, divorced: $\left.4.7 \pm 1.9 ; t_{28}=2.29, P=0.030\right)$. Accordingly, fledging success (i.e. percentage of eggs that resulted in fledglings) was lower in pairs that switched their partner (faithful: $0.75 \pm 0.06$, divorced: $0.45 \pm 0.17 ; t_{28}=2.24$, $P=0.033$ ). This effect was partly due to complete brood failures, which tended to be more common in broods where mate switching had occurred (faithful: 2/24 broods, divorced: 3/7 broods; Fisher's exact test: odds ratio 7.48, $n=31, P=0.062$ ). None of these brood failures were due to nest predation by Greater Spotted Woodpeckers or aesculapian snakes, both of which were common nest predators in our study area. It should be noted that of these five incidents of complete brood failures, three occurred in control plots (two faithful, one divorced) and two in experimental plots (both divorced; see Fig. 1). In one of the seven cases of within-season divorce, the brood was deserted during the incubation stage.

\section{Discussion}

Here we describe several cases of within-season divorce shortly before the onset of breeding in a wild population of Blue Tits. In total, $23 \%$ of pairs divorced, and at least one of the partners re-mated with a new territory holder. Within-season divorce was associated with fitness costs in that pairs that re-mated had a lower fledging success. However, due to the small sample size, these results have to be viewed with caution, and we therefore refrained from testing classical hypotheses to explain the observed cases of between-season divorce (Choudhury 1995). In the following, we discuss causes of within-season divorce and potential mechanisms responsible for the reduced breeding success.

There is no published data on within-season divorce in Blue Tits; as such, we are not able to link our observations to the naturally occurring rate of this type of divorce. The between-season divorce rate is around 50\% in our Blue Tit population (Valcu and Kempenaers 2008) and includes any change of partner between two breeding seasons irrespective of the timing of the partner change. It is possible that many of the reported cases of divorce occur shortly before breeding and that our results may reflect a natural rate of within-season divorce. Alternatively, the relatively high rate of within-season divorce in this study may have been due to the experimental disturbance at the original nestbox shortly before egg laying. All nestboxes in the control and experimental plots were temporarily removed from their original site and re-erected the following morning. This disturbance during the nest-building stage may have weakened the pair bond, leading several pair members to try and ensure breeding in the current season by re-mating with a new mate. Females that lost their nestbox in the experimental plots may have successfully out-competed other females throughout the entire study area. Indeed, in two cases, females from experimental plots re-mated with males from control plots (see Fig. 1), supporting the hypothesis that floating females may evict territorial females from their territory. This hypothesis is in line with studies documenting intense female-female competition and aggression for available nesting sites shortly before egg laying (Slagsvold and Lifjeld 1994) and is particularly prevalent in Blue Tits (Kempenaers 1995).

In our study, the breeding pairs showing within-season divorce had lower reproductive success than faithful pairs. These results are in contrast to previous findings in Blackcapped Chickadees showing that females benefitted from within-season divorce by re-mating with a male of higher quality (Otter and Ratcliffe 1996; Ramsay et al. 2000). The reduced fledging success in our study was partly explained by total brood failures during the incubation or nestling phase, which were equally common in control $(n=3$; two faithful, one divorced) and experimental ( $n=2$; two divorced) broods. More studies on the fitness consequences of within-season divorce are certainly needed since our results are based on a small sample size and, additionally, on the occurrence of complete brood failures, which may be due to chance events like the death of one pair member. Alternatively, the reduced breeding success may be due to the nest-site limitation experiment that altered breeding conditions in the whole study area. Increased competitive interactions around nestboxes may have continued during the incubation and nestling phase, assuming that evicted individuals remained within the study site. The extra investment in territorial defence may trade-off with brood care or survival, and there may be additional direct negative effects of the presence of floaters on reproductive performance. In one experimental box, we found dead nestlings with open head wounds that most likely originated from attacks by adult conspecifics. This type of injury had never been observed before in this study population. Alternatively, the rapid change of partner shortly before egg laying may have altered a male's perceived confidence in paternity, and this may negatively affected paternal investment (Whittingham et al. 1992; Sheldon 2002) and may partly explain the complete brood loss via 
brood desertion of the male in the control and experimental plots.

In contrast to other studies on within-season divorce (Otter and Ratcliffe 1996; Ramsay et al. 2000), we were unable to demonstrate any fitness benefits of a rapid change of partner before breeding onset. However, under conditions of sudden nest-site limitation, evicted individuals may have only two alternatives: either initiate a fast change of breeding partner and thereby gain some reproductive success, or forego breeding for 1 year. Hence, within-season divorce may reflect a flexible strategy of short-lived species, such as the Blue Tit, aimed at maximizing the probability to reproduce in the current season. This concept of flexibility in mate choice is partly in line with a study on European Starlings, which demonstrated that females adopt a similar re-mating strategy once their partner had disappeared or died shortly before breeding (Pinxten et al. 1993). To assess the adaptive value of within-season divorce, it would be necessary to compare the residual reproductive success of individuals that switched their partner shortly before egg laying with individuals that forewent a breeding bout. The fitness consequences of divorce are complex, but our results suggest that divorcing shortly before the onset of breeding may incur higher fitness costs compared to divorce and re-mating during the non-breeding season, thereby highlighting the importance of the optimal timing for mate-switching.

\section{Zusammenfassung}

Scheidung von Paaren innerhalb einer Brutsaison in Blaumeisen Cyanistes caeruleus

Scheidungen innerhalb einer Brutsaison, d.h. der Wechsel des Brutpartners während der alte Partner noch am Leben ist, wurde bei einigen Vogelarten ausführlich untersucht. Scheidung wird gesehen als das Ergebnis von Fortpflanzungsentscheidungen von Individuen zur Maximierung der eigenen Fitness, oder als Ergebnis intrasexueller Konkurrenzkämpfe um Paarungspartner. Im Gegensatz dazu hat Scheidung innerhalb einer Brutsaison-auch rapid mate switching genannt-deutlich weniger Aufmerksamkeit erhalten. Scheidungen innerhalb der Brutsaison können nach plötzlichen Veränderungen der Umweltbedingungen auftreten, zum Beispiel wenn Nistplätze verschwinden oder Territorien entwertet werden, oder wenn bessere Paarungspartner zugänglich werden. Scheidungen innerhalb einer Saison können von einem Mitglied des Paares initiiert werden, oder es kann das Ergebnis einer Übernahme durch ein ungepaartes Individuum sein, das um Zugang zu Ressourcen konkurriert. In einem Feldexperiment haben wir die Auswirkungen von limitierten Neststandorten auf das
Fortpflanzungsverhalten von Blaumeisen untersucht. Wir fanden mehrere Fälle von Scheidung innerhalb einer Brutsaison. Die Scheidungsrate hing nicht mit der experimentell begrenzten Beschränkung der Neststandorte zusammen, aber Paare die Partner wechselten, hatten geringeren Bruterfolg als treue Paare. Obwohl keine Unterschiede im Zeitpunkt des Brütens, Gelegegröße oder Schlupferfolg festgestellt wurden, hatten Paare mit einem neuen Partner einen niedrigeren Ausflugserfolg, was zum Teil durch den Verlust kompletter Bruten erklärt werden konnte. Diese Studie zeigt, dass die Paarbindung vor der Eiablage instabil sein kann, wenn Individuen gezwungen sind um neue Partner oder Neststandorte zu konkurrieren. Außerdem betont unsere Arbeit die Bedeutung des Zeitpunkts der Scheidung innerhalb des Brutzyklus.

Acknowledgments We thank Kees van Oers, Cornelia Ebert, Kim Teltscher, Agnes Tuerk and Zeynel Arslangündogdu for help during the field work. In addition, we thank two anonymous reviewers for constructive comments on the manuscript. The study received financial support from the Max Planck Society.

Open Access This article is distributed under the terms of the Creative Commons Attribution Noncommercial License which permits any noncommercial use, distribution, and reproduction in any medium, provided the original author(s) and source are credited.

\section{References}

Blondel J, Perret P, Galan MJ (2000) High divorce rates in Corsican blue tits: how to choose a better option in a harsh environment. Oikos 89:451-460

Cezilly F, Johnson AR (1995) Re-mating between and within breeding seasons in the greater flamingo Phoenicopterus ruber roseus. Ibis 137:543-546

Choudhury S (1995) Divorce in birds-a review of the hypotheses. Anim Behav 50:413-429

Ens BJ, Choudhury S, Black JM (1996) Mate fidelity and divorce in monogamous birds. In: Black JM (ed) Partnerships in birds: the study of monogamy. Oxford University Press, Oxford, pp 344401

Gowaty PA, Bridges WC (1991) Nestbox availability affects extrapair fertilizations and conspecific nest parasitism in eastern bluebirds, Sialia sialis. Anim Behav 41:661-675

Green DJ, Krebs EA, Cockburn A (2004) Mate choice in the brown thornbill (Acanthiza pusilla): are settlement decisions, divorce and extrapair mating complementary strategies? Behav Ecol Sociobiol 55:278-285

Heg D, Bruinzeel LW, Ens BJ (2003) Fitness consequences of divorce in the oystercatcher, Haematopus ostralegus. Anim Behav 66:175-184

Jacot A, Valcu M, van Oers K, Kempenaers B (2009) Experimental nest site limitation affects reproductive strategies and parental investment in a hole-nesting passerine. Anim Behav 77:10751083

Jeschke JM, Kokko H (2008) Mortality and other determinants of bird divorce rate. Behav Ecol Sociobiol 63:1-9

Kempenaers B (1995) Polygyny in the blue tit-intra-sexual and inter-sexual conflicts. Anim Behav 49:1047-1064 
Kempenaers B, Everding S, Bishop C, Boag P, Robertson RJ (2001) Extra-pair paternity and the reproductive role of male floaters in the tree swallow (Tachycineta bicolor). Behav Ecol Sociobiol 49:251-259

Lack D (1968) Ecological adaptations for breeding in birds. Methuen, London

Linden M (1991) Divorce in great tits-chance or choice-an experimental approach. Am Nat 138:1039-1048

McNamara JM, Forslund P (1996) Divorce rates in birds: predictions from an optimization model. Am Nat 147:609-640

McNamara JM, Forslund P, Lang A (1999) An ESS model for divorce strategies in birds. Philos Trans R Soc Lond B 354:223-236

Moody AT, Wilhelm SI, Cameron-MacMillan ML, Walsh CJ, Storey AE (2005) Divorce in common murres (Uria aalge): relationship to parental quality. Behav Ecol Sociobiol 57:224-230

Newton I (1994) The role of nest sites in limiting the numbers of holenesting birds-a review. Biol Cons 70:265-276

Otter K, Ratcliffe L (1996) Female initiated divorce in a monogamous songbird: abandoning mates for males of higher quality. Proc $\mathrm{R}$ Soc Lond B 263:351-355

Pampus M, Schmidt KH, Wiltschko W (2005) Pair bond and breeding success in blue tits Parus caeruleus and great tits Parus major. Ibis 147:92-108
Pinxten R, Hanotte O, Eens M, Verheyen RF, Dhondt AA, Burke T (1993) Extra-pair paternity and intraspecific brood parasitism in the european starling, Sturnus vulgaris-evidence from DNA fingerprinting. Anim Behav 45:795-809

R Development Core Team (2008) An introduction to R: notes on R, a programming environment for data analysis and graphics. R Foundation for Statistical Computing, Vienna

Ramsay SM, Otter KA, Mennill DJ, Ratcliffe LM, Boag PT (2000) Divorce and extrapair mating in female black-capped chickadees (Parus atricapillus): separate strategies with a common target. Behav Ecol Sociobiol 49:18-23

Sheldon BC (2002) Relating paternity to paternal care. Philos Trans R Soc Lond B 357:341-350

Slagsvold T, Lifjeld JT (1994) Polygyny in birds-the role of competition between females for male parental care. Am Nat 143:59-94

Valcu M, Kempenaers B (2008) Causes and consequences of breeding dispersal and divorce in a blue tit, Cyanistes caeruleus, population. Anim Behav 75:1949-1963

Whittingham LA, Taylor PD, Robertson RJ (1992) Confidence of paternity and male parental care. Am Nat 139:1115-1125

Wysocki D (2004) Within-season divorce rate in an urban population of European blackbird Turdus merula. Ardea 92:219-227 